\title{
ENERGY ABSORPTION ANALYSIS OF RUPD
}

\author{
Satish Gombi ${ }^{1}$, Mahendra .S.B ${ }^{2}$, Amithkumar $\mathbf{H}^{3}$ \\ ${ }^{I}$ Assistant professor, Department of Mechanical Engineering, SIT Mangalore, VTU Belgaum \\ ${ }^{2}$ Assistant professor, Department of Mechanical Engineering, SIT Mangalore, VTU Belgaum \\ ${ }^{3}$ Assistant professor, Department of Mechanical Engineering, SIT Mangalore, VTU Belgaum
}

\begin{abstract}
When passenger car hits the truck-trailer at rear, it penetrates inside the truck bed called truck trailer under-ride crash. This is responsible for thousands of accidents, causing severe injuries and spot death. This is mostly due to the lack of effective guards. The Present work focuses on energy absorption analysis of a Rear under Run Protection Device (RUPD) under crash scenario. The aim of the study is to replace Steel RUPD with RUPD made of composite material to reduce weight of the vehicle. In this study carbon fibre reinforced plastic composites were selected due to their high specific strength and specific stiffness which make them a preferred candidate in the material selection for modern lightweight structures in automotive engineering which can contribute to the improvement of mileage in addition to safety of the occupants. The RUPD was modelled in CATIA. Finite element model was generated in HYPERMESH and analysed in LS-DYNA for both Carbon/Epoxy RUPD and Steel RUPD and observed that Carbon/Epoxy RUPD absorbs 50\% of kinetic energy; whereas steel RUPD absorbs 90\%. But weight of Steel RUPD is $75 \mathrm{~kg}$ whereas the weight of Carbon/Epoxy RUPD is less than Steel RUPD which found to be below $15 \mathrm{~kg}$. This results in weight reduction and increases mileage of the vehicle. Considering above advantage, composites can be potential candidate for RUPD.
\end{abstract}

Keywords- Carbon/Epoxy, Catia, Hypermesh, LS-Dyna, RUPD, Steel

\section{INTRODUCTION}

Every year thousands of vehicle occupants are killed or injured due to road accidents. Out of which $8 \%$ are due to large truck accidents. A vehicle with gross vehicle weight ratio more than $10000 \mathrm{lbs}(4536 \mathrm{~kg})$ is considered as trucks. These accidents are much more severe because of mass difference between trucks and the small vehicle. Truck underride accidents represent major part of the truck related accidents, and thousands of people are killed because of under ride crashes. With the development of society, people have more and more stringent demands for automobile passenger safety, fuel economy and light weighting degree. The automobile body light weighting can be achieved by structure modification or material replacement. The structure modification requires the changes of forming, welding and assembling systems which is costly, while material replacement needs fewer such changes. Furthermore, material replacement is generally more effective in automobile light weighting than structure modification. In order to reduce the automobile weight, aluminum alloy, high strength steel, composite material, and so on, are widely used as light weighting materials to replace the traditional material of mild steel. Rear Underride guard is one of the key structures in heavy trucks for which careful design and manufacturing should be considered in order to achieve good impact behaviour with reduced total weight of the vehicle. The Underride guard is the main structure for absorbing the energy of collisions. Since, suitable impact strength is the main expectation for such a structure. To be able to avoid under ride accidents, a truck rear guard must meet some geometrical and strength requisites, because rear end of the trucks usually present an aggressive profile to passenger vehicles, the correct positioning of the rear guard is of extreme importance, with ground clearance and distance from truck or trailer bed being factors that determine its effectiveness. To take maximum advantage of the energy absorption capacity of car front structure and to avoid the wedge effect, the ground clearance should never exceed $500 \mathrm{~mm}$, with $400 \mathrm{~mm}$ being preferable. To reduce the penetration of the car underneath the truck or trailer chassis, it is necessary to position the guard as rearmost as possible. Considering the strength requirements BEERMANN and RECHNITZER [1] have postulated that an underride guard able to withstand the impact at about $56 \mathrm{~km} / \mathrm{hr}[2,3]$.

The legal requirements of RUPD regulated by ECE's R58. An Indian regulation IS $14812-2005$ is derived from ECE R58 standard [4, 10]. Carbon fiber reinforced plastic (CFRP) laminates are used in various industrial fields because they have excellent properties in the specific strength and specific stiffness [5]. It can be observed that the mechanical properties are mainly dependent on the fiber orientation of Carbon/Epoxy composites. Which shows good agreement with $0^{0} / 90^{\circ}$ orientation [6]. It can be observed from the previous works that many under-ride impact analyses have been conducted, and this gave the idea to understand the behaviour of the structure under impact loads. It is also observed that under-ride crash analysis has been performed using advanced numerical tools such as Altair, Hyper-works, LS-Dyna 3D, Pam crash etc... Many of the research work have reduced the under-ride accidents by developing new designs for the under-ride guards. In addition to FE based analysis few authors have developed experimental test procedure for evaluating the impact guard. 
In some studies they have evaluated the behaviour of guard for different types of car impact. In some studies they have evaluated energy absorption behaviour for thermoplastic composites [7]. Most of the studies show that CFRP has good behaviour to resist impact loading. With increasing concerns on energy crisis and environmental protection, there have been growing applications of carbon fiber reinforced plastic (CFRP) in many engineering fields attributable to its considerable advantages of lightweight, high strength, high corrosion resistance and easy manufacturing.In this researchThe CFRP is considered as it has a potential of weight reduction in the automotive structure which can contribute to the improvement of mileage [8,9].

\section{MODELING}

CATIA stands for Computer Aided Three Dimensional Interactive Application is the most powerful and widely used CAD tool for modelling. CATIA is owned and developed by Dassault Systems of France. It is used by the automotive and aerospace industries for automobile and aircraft product design. Catia is a high end design tool, which gives good surface finish.

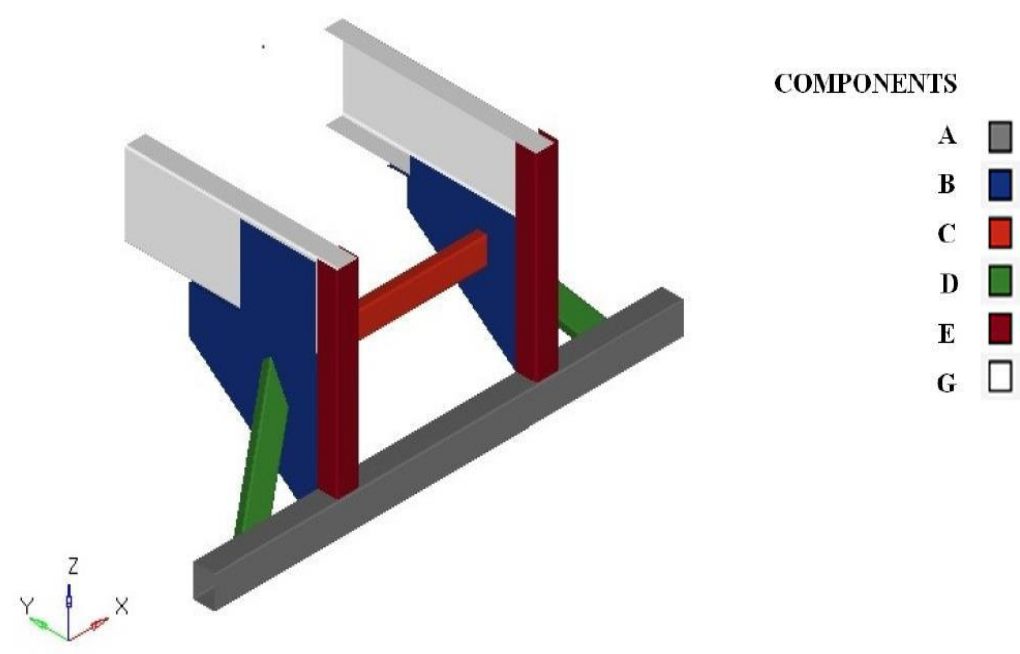

Fig 1: Nomenclature of RUPD

The guard shown in fig 1 consisted of a main beam A press-brake formed from a 5mm thick steel sheet, welded into two lateral supports(B) made of $7 \mathrm{~mm}$ thick steel sheets. These sheets were press-brake formed to provide the lateral supports with two flanges, one of which was designed to face the lower edge of the truck chassis beams $(\mathrm{G})$. The other formed one of the guard drop arms. Two angle braces (C) and a transversal reinforcement (D), both made of tabular 100 X 45 X 5 mm beams, strengthened the structure. Two more reinforcements (E) of U 98 X 58 X $8 \mathrm{~mm}$ beams were welded onto the drop arm flange of each lateral support. The whole structure weighted about $75 \mathrm{~kg}$ [1]. Here in present research using Catia V5 for modeling of the RUPD. Modeled RUPD is shown in Fig 2.

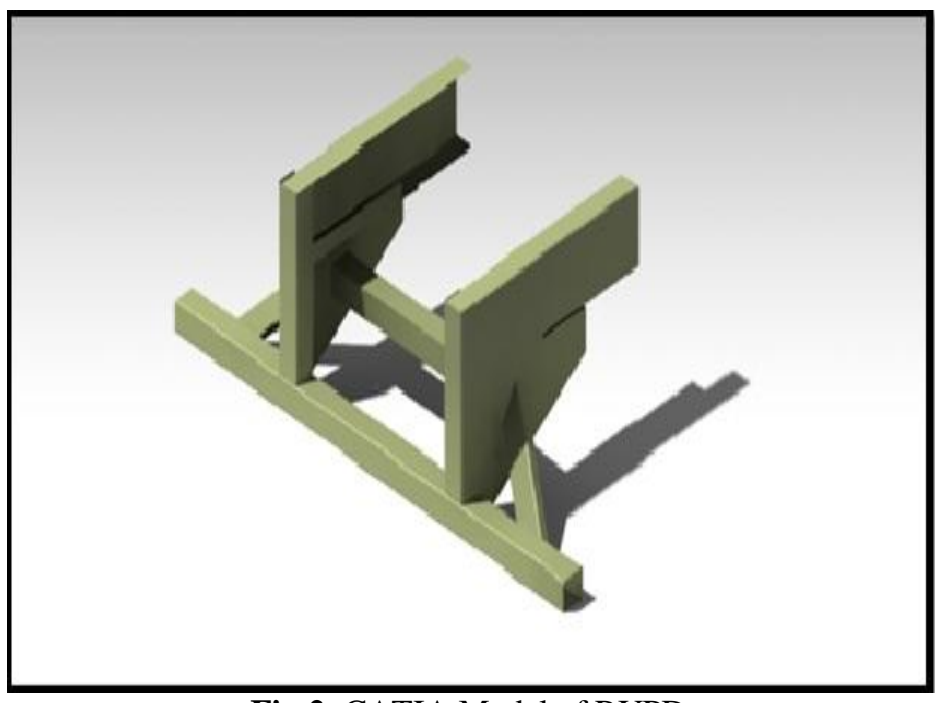

Fig 2: CATIA Model of RUPD 


\section{MESHING}

It is a finite element method, where the whole model is discretized into small elements. This approach of discretizing is called meshing. It can be carried out on the Catia model by using many of the meshing tools available in the market. The most widely used tool for structural components are HYPERMESH, ANSA, and PATRAN etc. Hypermesh is the most powerful pre-processor tool used over the globe for meshing. Around 50\% of the industries use Hypermesh as the meshing tool. Hence in present research make use of Hypermesh for finite element discretization, as its more users friendly as compared other meshing tools. Hypermesh is the best preprocessor, used in this research as a preprocessor, so in present research using Hypermesh for pre-processing.

The CATIA model was imported in Hypermesh. As shell-mesh couldn't be developed on the solid component, it requires a plate surface. Hence extracted mid-surface for every component of guard. The RUPD model is shell section, so the mesh used here is shell-meshing. Shell meshing comprises of quads and trias, but for a structural analysis only quads are preferred. In crash analysis the mesh elements size should always be $5 \mathrm{~mm}$ or less than $5 \mathrm{~mm}$. Taking into consideration the processor available, and global element size was 5mm. The Fig 3 represents the meshed model of RUPD. The model was meshed properly according to meshing rules. There were no opposite trias facing each other on a plane surface, Kinks were removed wherever it was generated, No trias at edges and the intersection of two components. Hypermesh allows us to perform all these quality checks, the present model acceptable for all the quality checks.

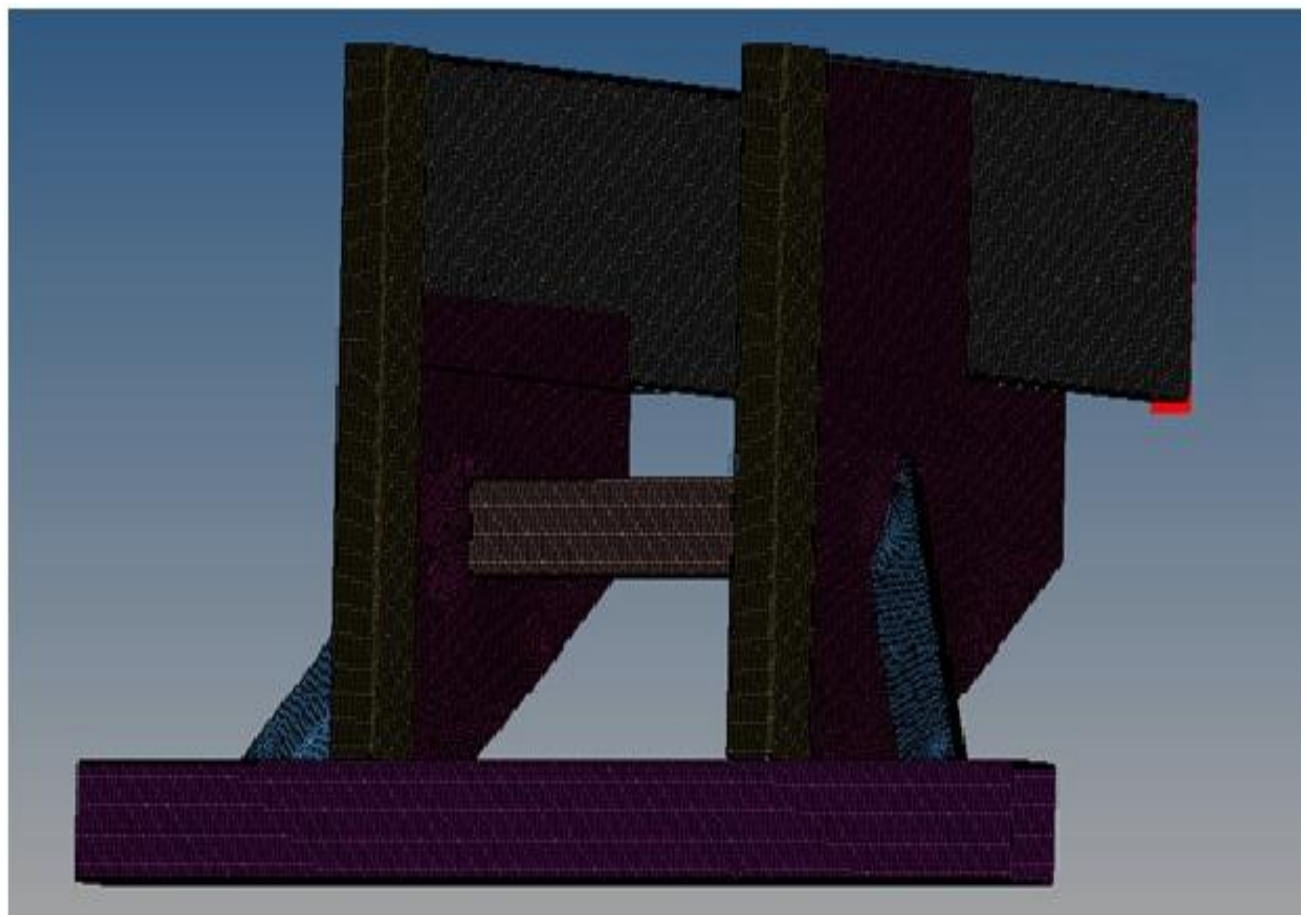

Fig 3: Meshed model of RUPD.

\section{GENERATION OF RIGID WALL AND ADDITION OF TRUCK WEIGHT TO THE SYSTEM}

As in the analysis developed a wall which will be fixed at a point and the model will be hitting the wall. So in order to develop a wall defined 'RIGID WALL PLANAR FINITE'. This card simply means that the wall is rigid, planar and has dimensions along its length and breadth. Here the wall developed is shown in the Fig 4. Creating the under-ride guard the fore-most important step is to assign the truck weight, to the system. Mass of truck along with the under-ride mass as cumulative, should be equal to the actual truck mass. This addition can be done through number of ways: here added it by extending the chassis section till the truck CG. This section is represented as a green color in Fig 5. 


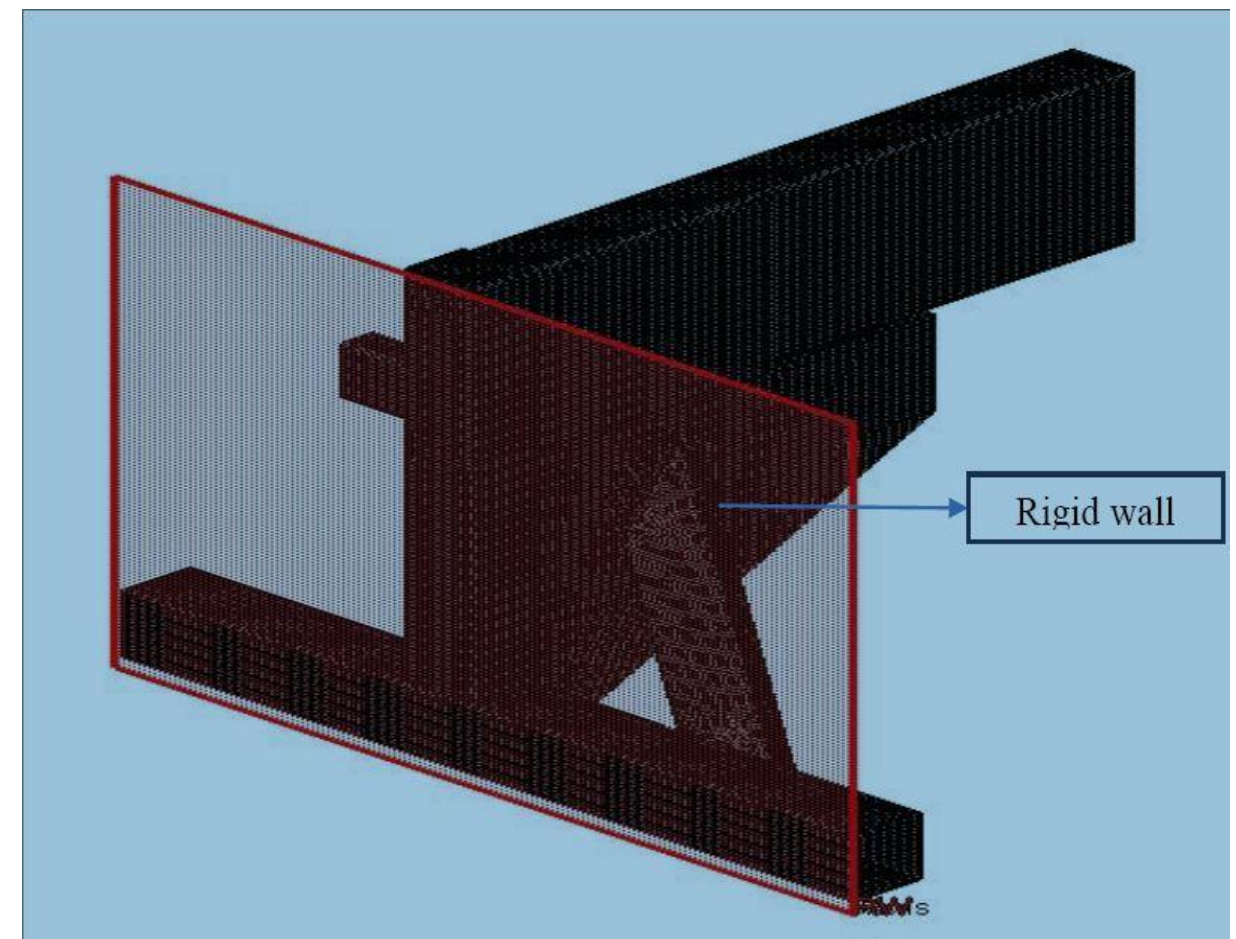

Fig 4: Rigid Wall generation for RUPD.

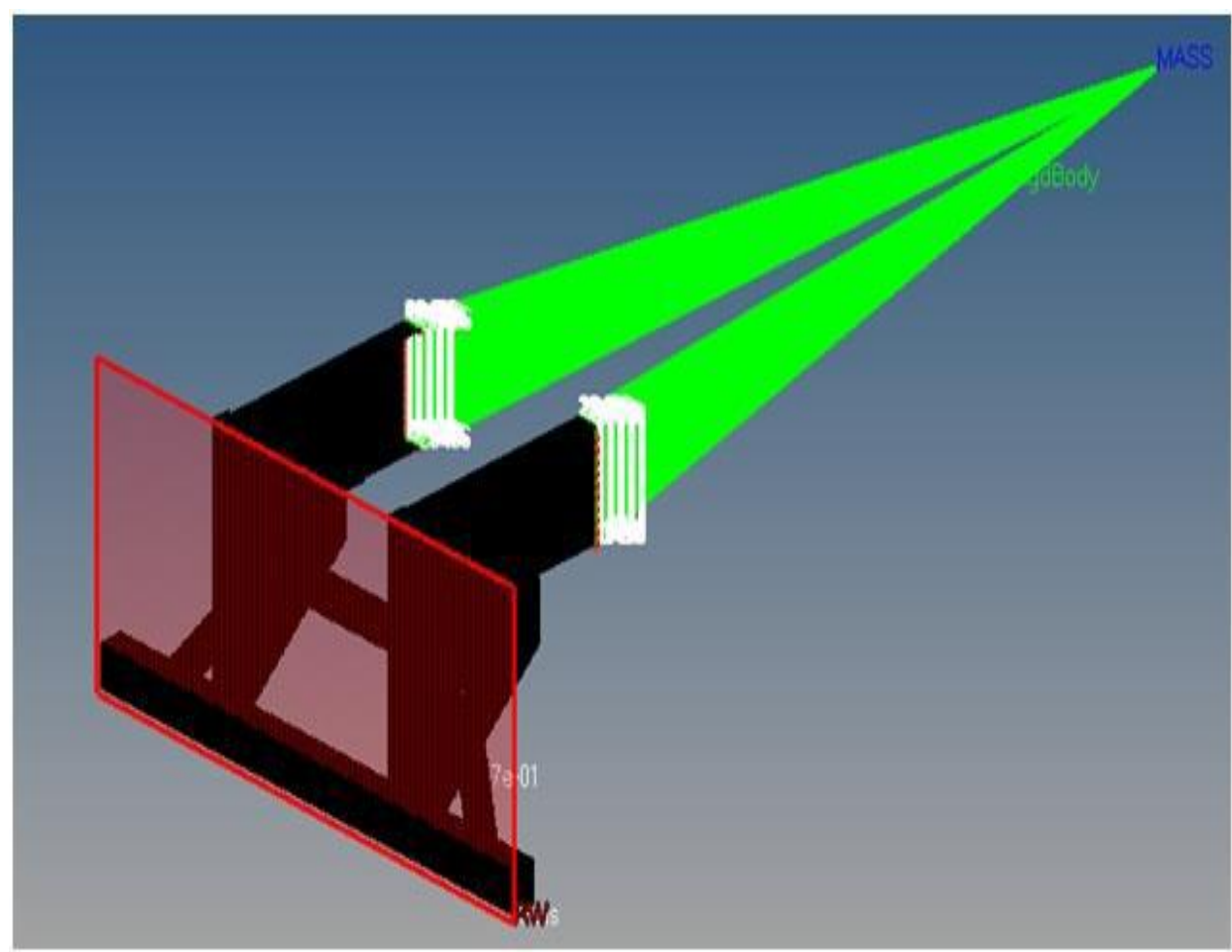

Fig 5: Addition of truck weight to the system.

\section{ANALYSIS}

It is a general-purpose, explicit and implicit finite element program used to analyze the nonlinear structural problems. It has fully automated contact analysis capability and error-checking features, which have enabled users worldwide over the globe to solve successfully many complex crash and forming problems. LS-DYNA 3D is one of the dynamic software's to study automotive crash and has many default input parameters tailored for crash simulations. For crash simulations, the explicit time integration is used due to advantages over the implicit method. In the explicit integration method, the solution is advanced without computing the stiffness matrix thus dramatically reducing the simulation time. So the present research making use of LS-DYNA 3D for the crash analysis of RUPD. 


\subsection{Carbon/Epoxy RUPD Results}

Here in this iteration run the model with the deck this has been set in the pre processor for Carbon/Epoxy RUPD. After giving the run in Ls-Dyna 3D the RUPD model is viewed in animation for 0.018 second (Refer fig 6) for Carbon/Epoxy composite.

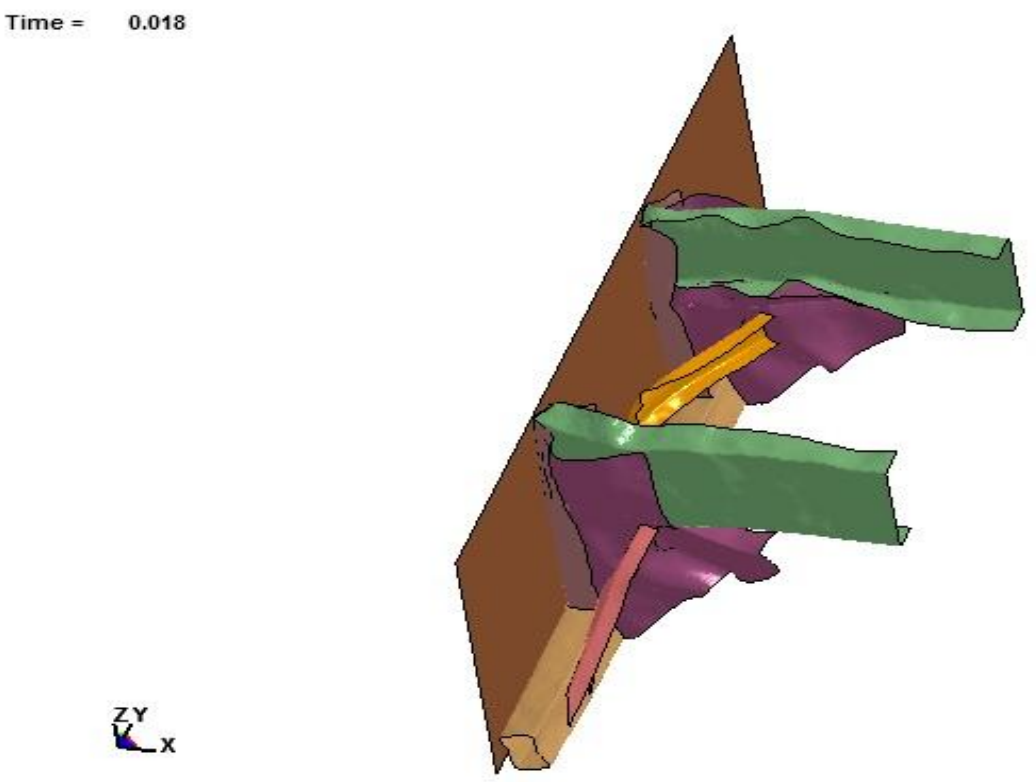

Fig 6: Ls-Dyna under-ride crash of Carbon/Epoxy RUPD.

\section{Global Energy plots of Carbon/Epoxy RUPD:}

In post-processing first checked the Energy plots which consists of internal, kinetic and total energy plots. Fig 7 shows the Global energy plots. Observed that kinetic energy reduces, and internal energy absorption increases and the total energy remain constant. As analysed with the Composite rear under run protective device found that maximum internal energy absorption is found to be $0.4 \times 10^{09}$ joules and kinetic energy reduces to $0.2 \times 10^{09}$ joules and the total energy remained constant.

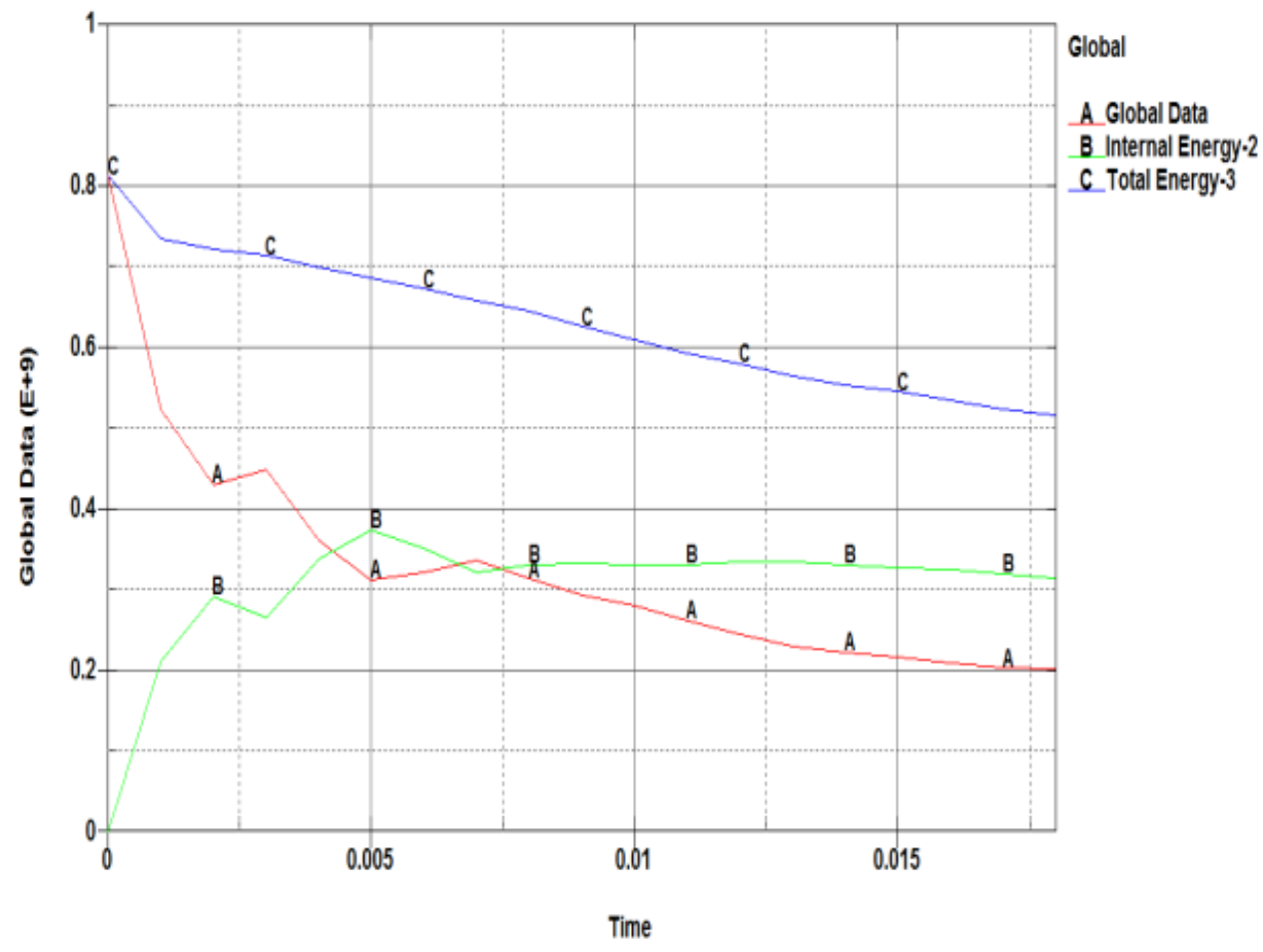

Fig 7: Global Energy plots of Carbon/Epoxy RUPD. 


\subsection{Steel RUPD Results}

Present day's candidate material for under ride guard is Steel 1020 since it is available for low lost and manufacturing is easy. Here run the model with the deck which has been set in the pre processor for Steel RUPD. After giving the run in Ls-Dyna 3D the RUPD model is viewed in animation and End time termination for Steel RUPD is found to be 0.02 seconds as shown in figure 8.

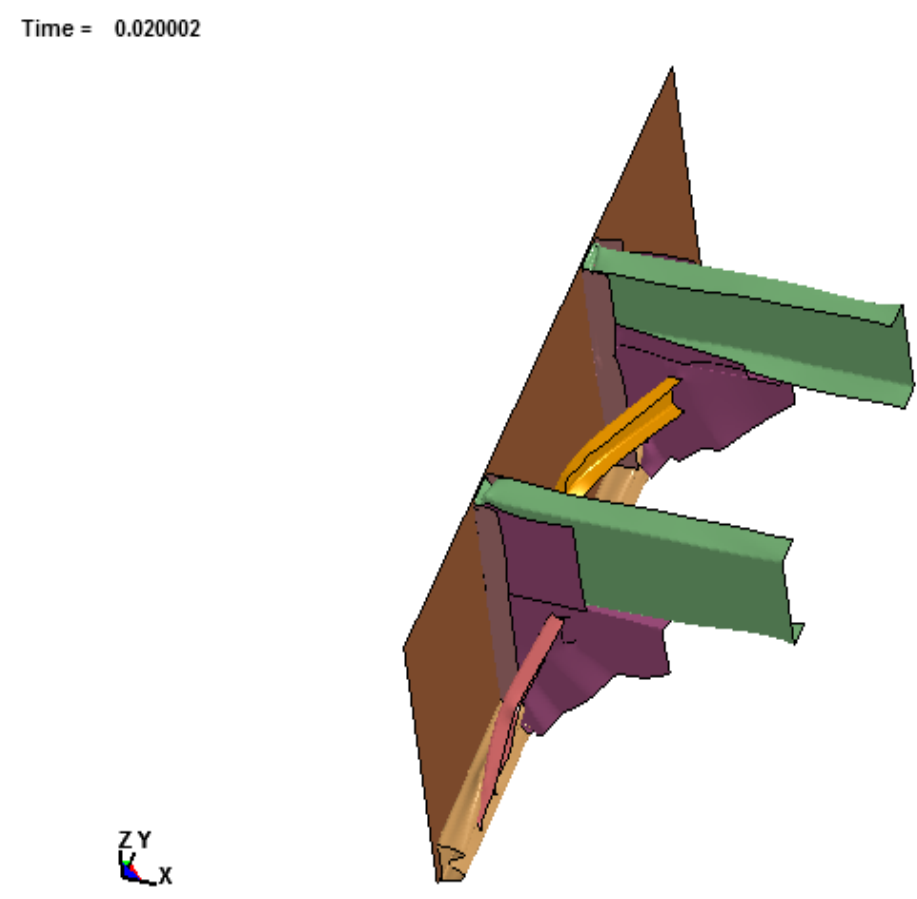

Fig 8: LS-Dyna 3D under-ride crash of Steel RUPD.

\section{Global energy plots of Steel RUPD:}

The global energy plots for steel 1020 shows that curves were smooth. Energy absorption of steel is found to be $0.7 \times 10^{09}$ joules and kinetic energy almost reduces to zero and total energy remained constant as shown in fig 9.

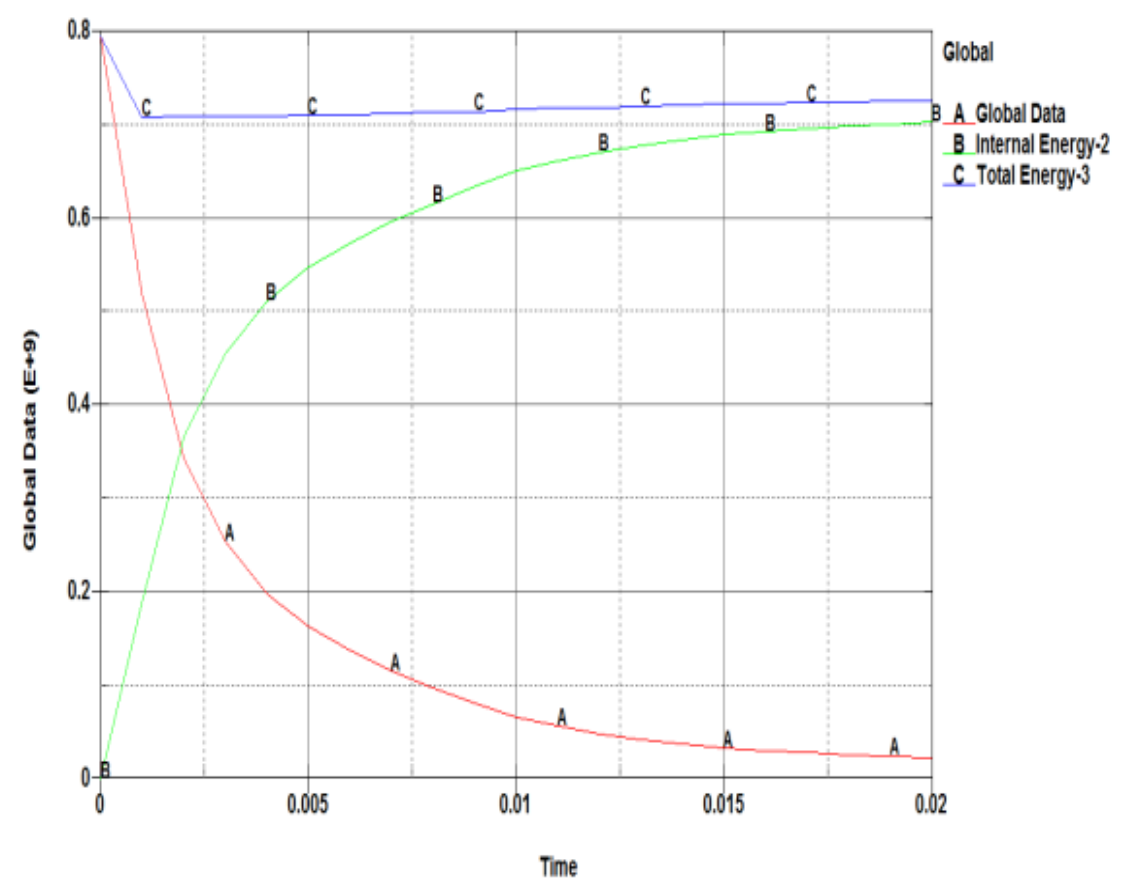

Fig 9: Global Energy plots of Steel RUPD. 


\subsection{LS-DYNA Results Comparison for Both} Carbon/Epoxy RUPD and Steel RUPD.

Since the both the global energy plots values of kinetic energy before impact are same for Carbon/Epoxy RUPD Steel RUPD i.e. $0.8 \times 10^{9}$ Joules (Refer fig 7, 9), and conclude that the deck is been set properly.

Energy absorbed by Composite is $0.4 \times 10^{09}$ joules.

Energy absorbed by Steel is $0.7 \times 10^{09}$ joules.

\section{CONCLUSION}

In this project, a detailed energy absorption analysis of Carbon/Epoxy composite RUPD and Steel RUPD was carried out numerically. The energy absorption behaviour of the Carbon/Epoxy RUPD was carried out. The main aim was to see that the car does not penetrate under the truck bed. The energy absorption was progressive and increased with decrease in kinetic energy, and total energy remained constant. The analysis was carried for Carbon/Epoxy Composite RUPD and Steel 1020 RUPD, Steel RUPD shows the good behaviour as it absorbs $90 \%$ kinetic energy where as Composite RUPD absorbs 50\% of kinetic energy.

Steel RUPD shows good performance in Energy Absorption. But weight of Steel RUPD is $75 \mathrm{~kg}$ whereas the weight of Carbon/Epoxy RUPD was very less than that of Steel RUPD which was found to be below $15 \mathrm{~kg}$. Which gives weight reduction and resulting in mileage of the vehicle.

Carbon/Epoxy RUPD absorbs almost 50\% of kinetic energy but cost of material is high if mass production rate increases its cost will decrease. In other ways its weight is very low only $20 \%$ of steel, so as weight of the truck decreases fuel consumption decreases and efficiency of the vehicle is improved. Considering the above advantage composites can be potential candidate for RUPD.

\section{SCOPE FOR FUTURE WORK}

As time and effort are limited, there are many aspects of the work that can be improved upon and extended. Some are:

$>$ Use of different composite materials so that underride guard performs better than Carbon/Epoxy composite.

$>\quad$ The present study limits the analysis to study the effect of energy absorption to only in $0^{0} / 90^{\circ}$ orientation. Further work can be extended to study the effect energy absorption with different orientation.

$>$ Co-relate the results obtained from the software to experimental results i.e. developing a physical model of under-ride guard using different materials and conducting crash test on under-ride guard.

$>$ Consider the side impact also.

\section{REFERENCES}

[1]. Jose Ricardo, Lenzi Mariolani, Antonio Celso Fonseca De Arruda, Luis Otto Faber Schmutzler, "Development Of New under ride Guards for Enhancement of Compatibility between Trucks and Cars", State University of Campinas, Brazil, Paper Number 425.

[2]. Matthew L. Brumbelow and Laura Blanar, "Evaluation of US Rear Underride Guard Regulation for Large Trucks Using Energy Real-World Crashes", Paper Number: 201022-0007.

[3]. Denis Boucher and Daniel B.T. Davis, "Trailer Underride Protection - A Canadian Perspective", SAE Paper No: 2000-01-3522.

[4]. Alok Kumar Khore, Tapan Jain, Kartikeya Tripathi "Multidisciplinary Design Study of Heavy Vehicle RUPD Crashworthiness and Energy Absorption" IOSR Journal of Engineering. ISSN (e): 2250-3021, ISSN (p): 2278-8719 Vol. 04, Issue 01 (January. 2014), Volume (3) PP 48-55.

[5]. S.Jeyanthi and J Janci Rani "High velocity impact analysis of the thermoplastic bumpers in automobiles" Journal of scientific and industrial research, Volume no 73, January 2004, pp66-68.

[6]. George C. Jacob, John F.Fellers, Srdan Simunovic, J. Michael Starbuck. "Energy Absorption in Polymer Composite Materials for Automotive Crashworthiness" Submitted thesis, University of Tennessee, Knoxville, USA. [7]. K. G. Satish, B.Siddeswarappa, K. Mohamed Kaleemulla "Characterization of In-Plane Mechanical Properties of Laminated Hybrid Composites" Journal of Minerals \& Materials Characterization \& Engineering, Vol. 9, No.2, pp.105-114, 2010.

[8]. Prashanth Banakar and H.K. Shivananda "Preparation And Characterization Of The Carbon Fiber Reinforced Epoxy Resin Composites" IOSR Journal of Mechanical and Civil Engineering (IOSRJMCE) ISSN : 2278-1684 Volume 1, Issue 2 (May-June 2012), PP 15-18.

[9]. G.Ben, and N.Sugimoto "Impact Behavior and Optimum Design of CFRP/Al Hybrid Beam In Side Collision Of Automobiles" Submitted thesis, Nihon University, 275 8575, Izumicho, Narashino, Chiba, Japan.

[10]. E. C. E. (1983) - Regulation No. 58 - Uniform provisions concerning approval of goods vehicles, trailers and semi-trailers with regard to Mariolani 10 their rear underrun protection. Economic Commission for Europe of the United Nations, July 11, 1983.

\section{BIOGRAPHIES}

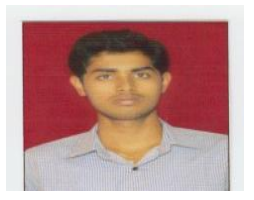

Satish Gombi M.Tech Machine Design working as Asst Prof in Mechanical Dept of Srinivas Institute of Technology Mangalore.

E-mail: asatishbjp@gmail.com

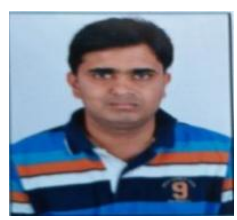

Mahendra. S. B. [M.Tech], PDM working as Assistant Professor in Srinivas Institute of Technology Mangalore. E-mail: mahendragshalli@gmail.co 
Amitkumar. H. [M.Tech] working as Assistant Professor in Srinivas Institute of Technology Mangalore.

E-mail: amitkumar.h3@gmail.com 